\title{
DISTINCT ARRAY COMPARATIVE GENOMIC HYBRIDIZATION PROFILES IN ORAL SQUAMOUS CELL CARCINOMA OCCURRING IN YOUNG PATIENTS
}

\author{
Esther M. O'Regan, BDSFDS, ${ }^{1}$ Mary E. Toner, FRCPath, ${ }^{1}$ Paul C. Smyth, $\mathrm{PhD},{ }^{2}$ \\ Stephen P. Finn, PhD, ${ }^{2}$ Conrad Timon, FRCS, ${ }^{3}$ Susanne Cahill, BSc, ${ }^{2}$ \\ Richard Flavin, MRCPath, ${ }^{2}$ John J. O'Leary, DPhil, ${ }^{2}$ Orla Sheils, PhD $^{2}$ \\ ${ }^{1}$ Department of Oral Surgery, Oral Medicine and Oral Pathology, Dublin Dental School and Hospital, Dublin, \\ Ireland. Specialist Registrar in Oral Pathology, Department of Histopathology Research, R0.35, Basement, Trin- \\ ity Centre for Health Sciences, St. James's Hospital, James's St, Dublin 8, Ireland. E-mail: emoregan@tcd.ie \\ ${ }^{2}$ Department of Histopathology Research, University of Dublin, Trinity College, Dublin, Ireland \\ ${ }^{3}$ Department of Otolaryngology and Head and Neck Surgery, St. James's Hospital, Dublin, Ireland
}

Accepted 28 July 2005

Published online 9 February 2006 in Wiley InterScience (www.interscience.wiley.com). DOI: 10.1002/hed.20354

\begin{abstract}
Background. Oral cancer typically affects smokers older than 50 years of age. Recently, however, a marked increase in the number of patients 40 years old and younger, many with no history of tobacco smoking, has been noted. Studies in this age group have so far been restricted to genomic areas well recognized as abnormal in typical patients with oral cancer. The aim of this study was to assess genomic aberrations in oral cancer, using comparative genomic hybridization (CGH) microarray technology, and to compare the genomic aberration profile of patients older than 40 years old with those 40 years old and younger.

Methods. Tumor samples from 20 patients with oral cancer (age range, 21-78; 10 smokers and 10 nonsmokers) were laser microdissected, and array CGH was used to identify genomic imbalances in these two cohorts.

Results. The older cohort showed high numbers of gains and losses in contrast to very few copy number changes in the younger nonsmoker cohort. In concurrence with the literature, tumors from the older cohort manifested deletions involving $3 p$ and 9p21 and gains involving 3q, 5q, 7p, 8q, 11q, and 20q. The younger group, particularly the nonsmokers, showed very few
\end{abstract}

Correspondence to: E. O'Regan

Contract grant sponsor: Cancer Research Ireland.

() 2006 Wiley Periodicals, Inc. changes overall, and the aberrations were not in the sites classically associated with oral cancer. Deletion of CDKN2A (p16) was completely absent in the younger group but was present in $50 \%$ of the older cohort.

Conclusions. We have demonstrated that there is far less genomic instability in young nonsmokers with oral cancer than found in typical patients with oral cancer. These observations indicate that oral cancer presenting at a younger age, particularly in nonsmokers, has a genomic profile different from the classically described oral cancer. (C) 2006 Wiley Periodicals, Inc. Head Neck 28: 330-338, 2006

Keywords: oral cancer; young patients; squamous cell carcinoma; array; CGH

Oral squamous cell carcinoma (SCC) is the sixth most common malignancy worldwide and shows a strong association with tobacco use. ${ }^{1}$ This disease is rare in patients aged 40 years and younger, being primarily a disease that occurs in men in their sixth and seventh decades. Ninety-five percent of oral SCCs occur among persons older than the age of 40 , with 60 being the average age at diagnosis. $^{2}$ The incidence of oral cancer in young 
adults ranges between $0.4 \%$ and $5.5 \% .^{3}$ Recently, however, there have been reports of a rising incidence of oral cancer among young adults in both Europe and the United States. ${ }^{4-6}$ In contrast to the conventional patient with oral cancer, a significant proportion of these young patients seem to have an absence of traditional risk factors. ${ }^{7,8}$ It has been suggested that oral cancer in the young may be a disease distinct from that occurring in older patients, with possibly a different etiology and disease progression. ${ }^{9}$ Potential factors accounting for this increase in incidence of oral SCC in this age group are diverse and could reflect changes in dental care, diet, food processing, nutritional supplementation, sexual habits, and their subsequent effect on biologic processes. However, there remains no clear evidence to support the significance of any single determinant.

One of the key features in the pathogenesis of many solid cancers, especially head and neck cancer, is chromosomal instability, with gene gain or loss reflecting this genetic instability. Genetic alterations have been recognized as important events in oral carcinogenesis. Technologic progress in molecular genetics and cytogenetics has allowed identification of some of the critical events associated with the development of oral cancer. ${ }^{10,11}$ Comparative genomic hybridization $(\mathrm{CGH})$ is a cytogenetic method that is capable of detecting and mapping relative DNA sequence copy number variation across the whole genome in one single experiment. It has been widely used to screen for multiple chromosomal aberrations in a variety of cancers ${ }^{12,13}$ and can help identify genes involved in cell growth and tumorigenesis. There are, however, some limitations, which include the inability to identify balanced chromosomal abnormalities and a limited mapping resolution, which may lead to small regions of genetic alterations being overlooked. Also, regions with complex aberrations containing both gains and losses may not be properly explained. For conventional CGH, the crucial detection size is estimated to be in the range of 10 to $20 \mathrm{Mb}$ and is homogeneous along the chromosomes (except around the centromeres). ${ }^{14}$ The sensitivity of CGH can be hampered by contamination of tumor material with normal cells (ie, stromal cells and inflammatory cells). The effect of this is to decrease the sensitivity of the technique, allowing some chromosomal aberrations to go undetected. To avoid this issue, a laser capture microdissection system (Arcturus PiXCell 11 Abott Laboratories, Abott Park, ILL) was used in this study, thus ensuring a pure population of tumor cells was obtained.

Microarray analysis is now a foundational technology allowing the analysis of DNA sequence vari- ation, gene expression, and protein levels in tissues and cells in an extensive parallel format. Since the development of microarrays, recognized limitations of conventional CGH have been overcome by coupling it to microarray technology, providing us with a platform for aberration detection that has improved sensitivity, improved resolution, improved reproducibility, and higher throughput. ${ }^{15}$

In array $\mathrm{CGH}$, metaphase chromosomes of the classical CGH technique are replaced by a highdensity array of genomic clones (eg, bacterial artificial chromosomes [BACs], or P1-derived artificial chromosomes [PAC]) on a solid surface. This combination of CGH with an array format has overcome some of the limitations of conventional CGH.

The GenoSensor array 300 system (Vysis, Downer's Grove, IL) is a recently developed system and comprises an array of 287 DNA targets cloned from BAC and PAC libraries and spotted in triplicate. These targets represent genomic regions that have demonstrable significance in cytogenetics and oncology. This array system provides a powerful tool for genome-wide evaluation of genomic instability manifest as copy gain and loss. Using the GenoSensor system, the resolution can be as low as $100 \mathrm{~Kb}$ for some targets, although it is not homogeneous along the chromosome. The approximate coverage for each chromosome is $40 \mathrm{Mb}$. A fully annotated list of the targets is available at http://www.vysis.com.

Previous studies have discussed the increasing incidence of cancer in young adults and have used a variety of upper age limits. The age limit is problematic, because youth is defined arbitrarily; however, most studies use 40 or 45 years old as the cutoff. ${ }^{16-19}$

Previous studies have analyzed chromosomal alterations in oral cancer ${ }^{20-25}$; however, few have applied array CGH technology. ${ }^{26-28}$ All CGH work on oral cancer so far in the literature has been directed at the typical patient with oral cancer (ie, the 60- to 70-year-old male smoker) and to date there are no references to array CGH studies of younger patients with oral cancer.

In this study, we have applied array CGH to oral cancer in patients older than 40 and patients 40 years old or younger to characterize the chromosomal imbalances underlying this disease.

\section{MATERIALS AND METHODS}

Patients. The St. James's Hospital and Federated Dublin Voluntary Hospitals Ethics Committee granted ethical approval, and informed con- 
sent was obtained from all patients before surgical treatment for oral cancer.

Fresh tumor samples were obtained from surgical resections of previously untreated oral SCCs. Smoking status was ascertained from the clinical notes. An attempt was made to categorize smoking status using pack-years; however, some packyear figures were not recorded in the notes. Smokers were defined as those who currently smoked tobacco, whereas nonsmokers were only considered for this study if they never smoked tobacco. The cohort contained no ex-smokers. Patients who were treated with radiotherapy before surgical resection were excluded. The study was restricted to SCCs of the oral cavity comprising tumors from the anterior two thirds of the tongue, alveolar ridge, palate, and floor of the mouth (Table 1). The acquired tissue was snap frozen and stored at $-80^{\circ} \mathrm{C}$ until analysis. A consultant pathologist verified the presence of SCC on a frozen section, according to standard criteria. For each case five frozen sections were cut and stained with hematoxylin-eosin. From each section, malignant epithelial cells were isolated to obtain pure populations of SCC using the Arcturus PixCell2 Laser Capture microdissection system.

Table 1. Clinicopathologic details of the patients with oral cancer included in this study.

\begin{tabular}{|c|c|c|}
\hline \multirow[b]{2}{*}{ Characteristic } & \multicolumn{2}{|c|}{ No. of patients by age } \\
\hline & $\leq 40 \mathrm{y}$ & $>40 y$ \\
\hline \multicolumn{3}{|l|}{ Number of patients } \\
\hline Male & 6 & 8 \\
\hline Female & 4 & 2 \\
\hline \multicolumn{3}{|l|}{ Tumor site } \\
\hline Tongue & 7 & 7 \\
\hline Floor of mouth & 1 & 1 \\
\hline Soft palate & 1 & 1 \\
\hline Alveolar ridge & 1 & 1 \\
\hline \multicolumn{3}{|l|}{ Smoking status } \\
\hline Smoker & $\begin{array}{l}4(\text { mean pack- } \\
\text { year }=16.5)^{\star}\end{array}$ & $\begin{array}{c}6(\text { mean pack- } \\
\text { year }=35)^{\star}\end{array}$ \\
\hline Nonsmoker & 6 & 4 \\
\hline \multicolumn{3}{|l|}{ Classification } \\
\hline $\mathrm{T} 1$ & 2 & 1 \\
\hline $\mathrm{T} 2$ & 5 & 4 \\
\hline T3 & 3 & 4 \\
\hline $\mathrm{T} 4$ & 0 & 1 \\
\hline NO & 4 & 3 \\
\hline $\mathrm{N}+$ & 6 & 7 \\
\hline \multicolumn{3}{|c|}{ Grade of differentiation } \\
\hline Well & 1 & 0 \\
\hline Moderate & 8 & 7 \\
\hline Poor & 1 & 3 \\
\hline
\end{tabular}

*Mean pack-year = mean of available pack-years (pack-years were unavailable in three samples).
DNA Extraction. DNA was extracted using a Puregene kit (Gentra, Minneapolis, MN) according to the manufacturer's instructions, which is available from the manufacturer's web site (www. gentra.com).

Size and concentration of the extracted DNA was confirmed by gel electrophoresis and optical density. A prerequisite of $100 \mathrm{ng}$ of DNA was the stipulated minimum starting material for the array CGH experiment.

\section{Array CGH.}

Labeling. The Vysis GenoSensor 300 labeling protocol was followed according to the manufacturer's instructions. Reference male and reference female DNA was provided by Vysis. Working solutions of the test and reference DNA at $25 \mathrm{ng} / \mu \mathrm{L}$ in $10 \mathrm{mM}$ Tris, $1 \mathrm{~m} M$ EDTA, pH 7.4-8.0, were made. Test and reference genomic DNA (100 ng of each, $4 \mu \mathrm{L}$ ) was labeled with Cy3 dCTP and Cy5 dCTP (PE Life Sciences, Boston, MA), respectively, by random priming using a Vysis Random Labelling kit. The DNA was mixed with the appropriate fluorescent dye in the presence of Klenow polymerase in a final volume of $100 \mu \mathrm{L}$ and incubated at $37^{\circ} \mathrm{C}$ for 2 hours. DNAse digestion was then performed, and the labeled DNA was recovered by precipitation and resuspended in $4 \mu \mathrm{L}$ of $10 \mathrm{mMTris,} \mathrm{pH}$ 8.0. At this stage, agarose gel electrophoresis was used to check the length of the DNA fragments. If the fragments were between 200 and $500 \mathrm{bp}$ in length, then the probes were considered optimal for hybridization.

Hybridization. For hybridization, the labeled test and labeled reference DNA were combined in equal volumes with hybridization buffer (containing Cot-1 DNA to block repetitive sequences), applied to the array surface, and coverslipped.

Each array was hybridized at $37^{\circ} \mathrm{C}$ in darkness for 60 to 72 hours in an airtight container, the atmosphere of which was saturated with $50 \%$ formamide $/ 2 \times \mathrm{SSC}$.

Washing. After removing the hybridization coverslip, each microarray was washed sequentially in $50 \%$ formamide $/ 2 \times \mathrm{SSC}$, followed by $\mathrm{l} \times \mathrm{SSC}$, and finally rinsed in distilled water. Array 4', 6-diamidino-2-phenylindole (array DAPI, $25 \mu \mathrm{L}$, Abbott Laboratories, Abbott Park, IL) was applied to the wet surface of the array, and the final coverslip was mounted. The arrays were stored in the dark for 45 minutes before reading. 
Reading. The GenoSensor Reader is a fluorescent imaging system that captures an image of the hybridized chip in three color planes: $\mathrm{Cy} 3, \mathrm{Cy} 5$, and DAPI blue. The Vysis GenoSensor Array 300 uses a CCD camera and a $175-\mathrm{W}$ xenon illumination source to capture three images of each microarray, specific for the DAPI counterstain (blue), the test DNA (green), and the reference DNA (red), respectively. The blue image is used to identify and localize the target spots on the grid. Once identified, the spots can then be quantitatively analyzed using specialized software, which integrates the green and red fluorescence intensities, subtracts the local background, and calculates the ratio of test intensity to reference intensity (T/R) for each spot (three replicate spots for each target gene). The background-corrected intensities were then used to determine the ratio of test intensity (green) to reference intensity (red) and, after further normalization, were used to estimate the relative abundance of a specific target sequence in the test DNA. The averaged $T / R$ ratios have to be normalized with respect to a $T / R$ control spot or $T / R$ group of spots. The Vysis system does this by detecting spots, which have apparently normal copy number, and dividing all $\mathrm{T} / \mathrm{R}$ ratios by the $\mathrm{T} / \mathrm{R}$ ratio of the "normal."

A control experiment was run in tandem with the experiment using cell line DNA ( $\mathrm{CoSH}$ mixture comprising three cell lines), which was provided by the manufacturer and has documented amplifications of a variety of oncogenes. Our results for the control run were concordant with those described by Vysis.

Statistical Analysis. Variation in the mean number of aberrations detected between the groups were tested using a Mann-Whitney $U$ test, and variation in specific targets between the groups was detected using the Fisher exact test. All of the statistical analyses were performed using SPSS 11.5 for Windows (SPSS, Inc, Chicago, IL).

\section{RESULTS}

Twenty samples met inclusion criteria. Tumors were all primary SCCs. Ten (50\%) samples were taken from oral cancer in nonsmokers, and 10 $(50 \%)$ were from smokers. All samples were from tumors of the oral cavity, with $14(70 \%)$ located in the anterior two thirds of the tongue.

$\mathrm{CGH}$ analysis revealed that genomic imbalances were a feature of every tested sample, although to varying extents across the sample cohorts.
Fluorescent ratios of the Cy3:Cy5 labeled DNA ranged from 0.22 to 6.62 . To determine the variations in the ratios of the spots in normal control DNA, comparative hybridizations using test and reference DNA from normal samples were performed. Mean ratio and standard deviation of the normal array CGH was 1.01 and 0.06 to 0.09 , respectively. A value of the mean ratio $\pm 2 \mathrm{SD}$ was set as the cutoff level for normal gene copy number. Ratios of higher than 1.19 and lower than 0.81 were considered to have copy gain and copy loss, respectively. The report generated by the GenoSensor Array 300 tabulates many variables including the assigned target number, target clone name, cytogenetic location, the number of spots included, and the normalized test to reference intensity (Figure 1).

Gain of genomic material was consistently more frequent in all groups than loss (Figure 2). The older cohort had a significantly higher number of aberrations per tumor (mean, 99; range, 32$164)$ than the younger group (mean, 57; range, 8 111) ( $p=.02)$, with the younger nonsmokers showing the lowest and the older smokers showing the highest number of aberrations ( $p=.04$ ) (Table 2). A linear trend was evident on further breakdown of the age groups, with an increase in the average number of aberrations correlating directly with an increase in age of the patient (Figure 3).

In the case of the Tclassification of the tumors, the number of aberrations did increase with increasing T classification; however, this trend was not statistically significant (Table 2). Classification T4 was excluded because of insufficient sample numbers. At any one target, the frequency of gains in the older group ranged from $0 \%$ to $67 \%$. The 25 most frequently aberrant loci in the classic head and neck squamous cell carcinoma (HNSCC) cohort (older smoker) are tabulated in the follow-

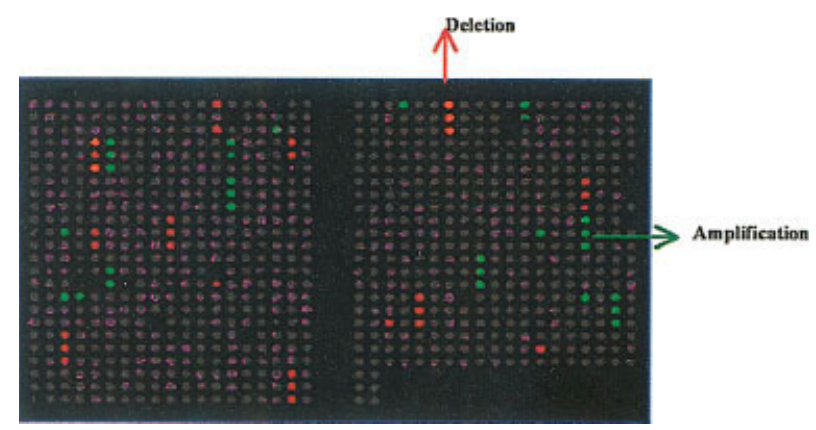

FIGURE 1. Microarray visualization showing a 9p21.3(MTAP) deletion (red) and 17q21 (BRCA 1) amplification (green). Only deletions or amplifications occurring in triplicate spots are considered to be valid. 


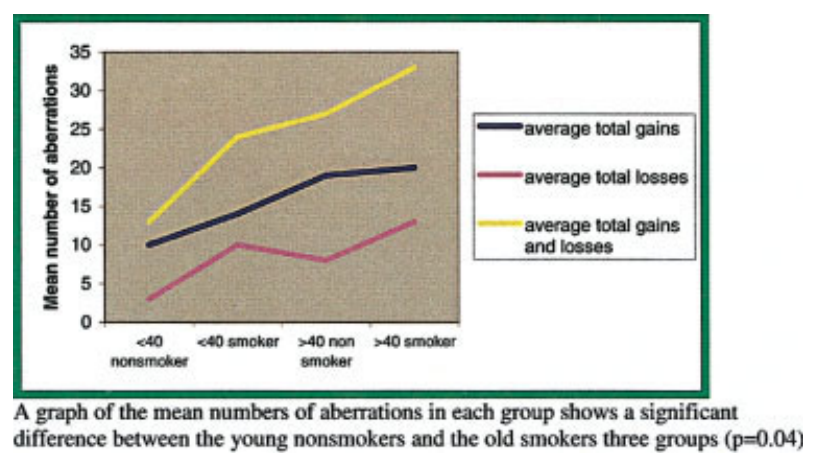

FIGURE 2. Mean numbers of gains and losses in each of the four cohorts.

ing (Table 3). Gains most commonly found in the older cohort occurred in clones mapping to $1 \mathrm{p}, 5 \mathrm{p}$, $7 \mathrm{p}, 11 \mathrm{p}$ (subtelomeric regions) and to $5 \mathrm{q} 33,11 \mathrm{q} 13$ (FGF4), and 22q13 (PDGFB), whereas clones mapping to $3 \mathrm{p}$ (subtelomeric region), 3p24 (THRB), and $9 \mathrm{p} 21\left(\mathrm{p} 16^{I N K 4}\right)$ were among the most frequently lost (Table 3). This profile of frequent gain and loss in the older group mirrors that found in the literature on oral SCC and HNSCC. Deletions of $p 16^{I N K 4}$ $(50 \%), 9_{\mathrm{p}} 11.2(70 \%)$, and 5q11.2 (MSH3) $(60 \%)$ were found exclusively in the older group. Overall, there was a significant difference found in the occurrence of deletions at $9 \mathrm{p} 21,9 \mathrm{p} 11.2,5 \mathrm{q} 11.2$, and $5 \mathrm{q} 21$ between the two groups (Fisher exact, $p<.01)$.

The profile of the younger cohort was markedly different from the older cohort in terms of copy gain and loss. The most frequent copy number changes were found in clones mapping to $1 \mathrm{p}$ and $3 \mathrm{p}$ (subtelomeric) and to 3q (MFI2), 11p (INS), and 11q13

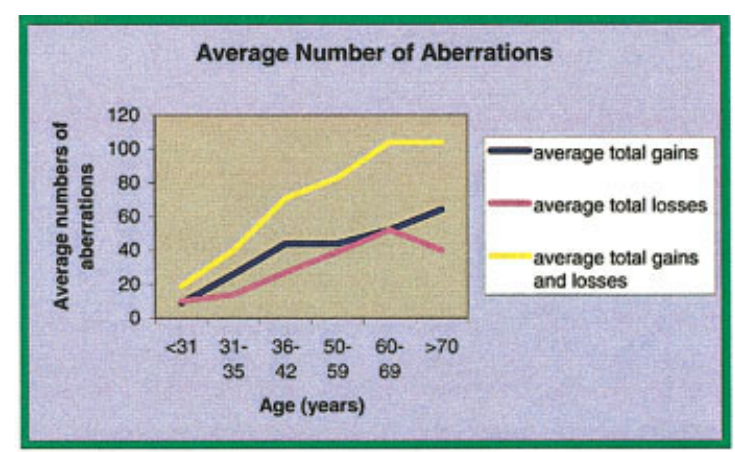

A graph of the mean numbers of aberrations in each group shows a significant difference between the young (under 40 years old) and the old (over 40 years old) $\mathrm{p}=0.02$

FIGURE 3. Average number of aberrations across the various age groups.

(FGF4), 11q13-q14 (PAK1), 14q32.1 (TCL1A), and 22q11.2 (TBX1) (Table 4).

\section{DISCUSSION}

Oral cancer is rare in patients younger than 40 years of age; however, recent reports on the incidence of oral cancer in young adults have shown an alarming increase of up to fivefold in Europe and in the United States. ${ }^{4,9}$

Historically, cytogenetic analysis of solid tumors has proven difficult, and although there are many techniques used for detection of genetic changes involved in solid tumors, all have their limitations. In 1992, Kallioniemi et $\mathrm{al}^{29}$ developed a molecular cytogenetic method capable of detecting and mapping relative DNA sequence copy number variation across the whole genome in one single experiment. CGH uses a relatively small amount of DNA and allows analysis of the whole

\begin{tabular}{lccc}
\hline \multicolumn{4}{c}{ Table 2. Analysis of numbers of aberrations by clinical details. } \\
\hline $\begin{array}{c}\text { Mean no. of } \\
\text { amplifications }(\%)\end{array}$ & $\begin{array}{c}\text { Mean no. of } \\
\text { deletions }(\%)\end{array}$ & $\begin{array}{c}\text { Total mean no. of } \\
\text { aberrations }(\%)\end{array}$ \\
\hline $\begin{array}{l}\text { Age, y } \\
\leq 40\end{array}$ & $70(24)$ & & \\
$>40$ & $104(36)$ & $48(16)$ & $118(40)$ \\
Smoking status & & $90(31)$ & $194(67)$ \\
Nonsmoker & $68(24)$ & $55(19)$ & $123(43)$ \\
Smoker & $106(37)$ & $83(29)$ & $189(66)$ \\
Age and smoking & $25(9)$ & $20(7)$ & $45(16)$ \\
$\leq 40$ nonsmoker & $45(16)$ & $28(10)$ & $73(26)$ \\
$\leq 40$ smoker & $43(15)$ & $35(12)$ & $78(27)$ \\
$>40$ nonsmoker & $61(21)$ & $55(19)$ & $116(40)$ \\
$>40$ smoker & & & .02 \\
T classification & $37(13)$ & $22(8)$ & $59(21)$ \\
T1 & $43(15)$ & $40(10)$ & $73(25)$ \\
T2 & $49(17)$ & & $93(32)$ \\
T3 & & & .04 \\
\hline
\end{tabular}

*p value for Mann-Whitney $U$ test. 
Table 3. The most frequent copy number imbalances in the older group and comparison with the younger group.

\begin{tabular}{|c|c|c|c|c|}
\hline \multirow[b]{2}{*}{ Chromosome } & \multirow[b]{2}{*}{ Gain/loss } & \multirow{2}{*}{$\begin{array}{c}\text { Clone name } \\
\text { (NCBI cytogenetic } \\
\text { locus) }\end{array}$} & \multicolumn{2}{|c|}{$\%$ of patients with aberrations } \\
\hline & & & $>40 y$ & $\leq 40 \mathrm{y}$ \\
\hline Chr 1 & Gain & 1ptel (subtelomeric) & 60 & 20 \\
\hline Chr 2 & Gain & 2qtel (subtelomeric) & 70 & 20 \\
\hline \multirow[t]{8}{*}{ Chr 3} & Loss & $3 p$ (subtelomeric) & 70 & 50 \\
\hline & Loss & 3p (subtelomeric) & 50 & 40 \\
\hline & Loss & THRB (3p24.3) & 60 & 20 \\
\hline & Loss & FHIT (3p14.2) & 50 & 30 \\
\hline & Loss & P44s 10 (marker) & 60 & 20 \\
\hline & Loss & ROBO1 (3p12-3p13) & 70 & 20 \\
\hline & Gain & TERC (3q26) & 50 & 40 \\
\hline & Gain & MFI2 (3q29) & 60 & 50 \\
\hline \multirow[t]{3}{*}{ Chr 5} & Loss & MSH3 (5q11.2-5q13.2) & 50 & 0 \\
\hline & Loss & $A P C(5 q 21-5 q 22)$ & 67 & 0 \\
\hline & Gain & CSF1R (marker) & 70 & 20 \\
\hline Chr 7 & Gain & EGFR (7p12.3-p12.1) & 50 & 30 \\
\hline \multirow[t]{2}{*}{ Chr 8} & Gain & FGFR1 (8p11.2-p11.1) & 60 & 20 \\
\hline & Gain & MYC (8q24.11-q24.13) & 80 & 30 \\
\hline \multirow[t]{2}{*}{ Chr 9} & Loss & $P 16$ (9p21) & 50 & 0 \\
\hline & Loss & AFM137XA11 (9p11.2) & 70 & 0 \\
\hline \multirow[t]{4}{*}{ Chr 11} & Gain & INS (11p subtelomeric) & 80 & 60 \\
\hline & Gain & P57 (KIP2) (11p15.5) & 50 & 30 \\
\hline & Gain & CCND1 (11q13) & 67 & 30 \\
\hline & Gain & FGF4 (11 q13) & 70 & 50 \\
\hline \multirow[t]{2}{*}{ Chr 14} & Gain & TCL1 (14q32.1) & 60 & 50 \\
\hline & Gain & $A K T(14 \mathrm{q} 32.32)$ & 80 & 40 \\
\hline Chr 22 & Gain & PDGFB (22q13.1) & 70 & 40 \\
\hline
\end{tabular}

genome detecting losses and gains in all chromosomes at once, without the need for cell culture. ${ }^{30}$ $\mathrm{CGH}$ has been previously applied in studies of classic oral cancer and has demonstrated a nonrandom pattern of genomic aberrations, including deletions of material from $3 p, 5 q$, and $9 p$ and gains involving $3 \mathrm{q}, 5 \mathrm{p}, 7 \mathrm{p}, 8 \mathrm{q}, 11 \mathrm{q}, 17 \mathrm{q}$, and $20 \mathrm{q} .^{23,26,27}$ Although CGH has been used to analyze oral cancer, this is the first CGH study in the literature comparing the profile of young patients with older more classic cases of oral cancer.
The aims of this study were twofold. First, we wished to map gains and losses in DNA from cases of oral cancer and compare our findings with those in the published literature. Second, we wished to compare the profile of younger patients with oral cancer with the profile found in older patients with oral cancer. This study shows for the first time by $\mathrm{CGH}$ analysis that the genomic profile of younger patients with oral cancer, especially the nonsmokers, differs markedly from the profile of the classic patient with oral cancer.

Table 4. The most frequent copy number imbalances occurring in the younger group and comparison with the older group.

\begin{tabular}{|c|c|c|c|c|}
\hline \multirow[b]{2}{*}{ Chromosome } & \multirow[b]{2}{*}{ Gain/loss } & \multirow[b]{2}{*}{ Clone name (locus name NCBI) } & \multicolumn{2}{|c|}{$\begin{array}{c}\% \text { of patients with } \\
\text { aberrations }\end{array}$} \\
\hline & & & $\leq 40$ y & $>40 y$ \\
\hline Chr 1 & Gain & $1 p$ (subtelomeric) & 50 & 30 \\
\hline \multirow[t]{2}{*}{ Chr 3} & Loss & $3 p$ (subtelomeric) & 50 & 70 \\
\hline & Gain & MFI2 (3q29) & 50 & 60 \\
\hline Chr 7 & Gain & EGFR (7p12.3) & 50 & 50 \\
\hline \multirow[t]{3}{*}{ Chr 11} & Gain & INS $11 \mathrm{p}$ (subtelomeric) & 60 & 80 \\
\hline & Gain & FGF4 (11q13) & 50 & 70 \\
\hline & Gain & PAK1 (11q13) & 50 & 40 \\
\hline Chr 13 & Gain & TCL1A (14q32) & 50 & 60 \\
\hline Chr 22 & Gain & $T B X 1(22 \mathrm{q} 11.2)$ & 50 & 40 \\
\hline
\end{tabular}


Mean Number of Aberrations. Chromosomal imbalance is thought to be the major type of genetic instability in solid tumors. ${ }^{31}$ In this study, the older group had high numbers of aberrations, occurring at classically described loci. On closer analysis of the two groups, it is notable that both the smokers, irrespective of age, and the older nonsmokers have high numbers of changes, whereas the younger nonsmokers had far fewer aberrations (Figure 3). This suggests that although the older nonsmokers are not directly exposed to the carcinogens, prolonged exposure in a secondary manner to similar carcinogens may be a factor contributing to the development of oral cancer in this group; however, because of lack of clinical details regarding lifestyle of the patients in this study, it is not possible to draw firm conclusions on the effects of environmental carcinogens. Of course, we cannot rule out the possibility that some of these aberrations are simply a result of aging; however, the aberrations found in the older nonsmokers closely resemble the chromosomal changes seen in all the smokers and those changes quoted in the literature.

The younger nonsmokers had considerably fewer aberrations than the other three groups, suggesting that chromosomal imbalance is not the main mode of genetic instability in this group.

In relation to tumor staging, an attempt was made to stage match the two cohorts; however, the older group had an extra T4, whereas the young group had an extra T1. Analysis of the 20 samples showed a slight increase in the number of aberrations with increasing stage; however, this was not statistically significant $(p=.1)$. Previous studies have found no difference in T classifications and numbers of aberrations. ${ }^{10}$

Specific Events. Over the years, classical cytogenetic analysis of head and neck tumors has been very productive, resulting in the identification of key genomic regions involved in the development and progression of HNSCC. Studies on oral cancer and HNSCC have shown that a number of chromosomal regions are consistently altered, such as gains on $3 q, 5 p, 8 q$, and $11 q 13$ and losses on $3 p$ and $9 p$ among others. ${ }^{20-23,32}$

Array CGH analysis of oral cancer cases in this study found that the most frequent alterations were mapped to chromosome 3 , with gain of the $q$ arm often occurring simultaneously with loss of the $\mathrm{p}$ arm. The "older group" in this study showed a profile similar to that of the "classic" patient with oral cancer in the literature, including dele- tions on $3 p$ and $9 p$ and gains of $3 q, 5 q, 7 p$, and $11 q$ 13 . In concordance with the literature on oral cancer, gain of the $q$ arm was a less frequent event than loss of the $p$ arm. ${ }^{22}$

Having established that the profile of the older group resembled closely that found in the literature, our second aim was to compare the genomic profile of the younger group with the older group. The changes occurring most frequently are tabulated in Table 3. Having established that there is less genomic instability in the younger cohort, especially the nonsmokers, we also note the very low number of similar genes altered across the younger group. The genes most commonly altered in this group are also altered in the older group; therefore, there is no genomic aberration that was exclusively gained or lost in the younger group. However, in the younger group, there is a notable absence of aberrations of genes that are thought to be of paramount importance in the development of oral cancer, such as $p 16$ deletions and $A P C$ deletions.

Of note, the younger group seem to have low frequencies of aberrations most commonly found in the literature, namely, loss of $p 16$ and loss of $A P C$ (Table 2).

Deletion of $C D K N 2 A$ ( $p 16^{I N K 4}$ ) has been associated in the literature with smoking. SanchezCespedes et al, ${ }^{33}$ in their studies of carcinomas of the lung, found that deletion of the $p 16$ gene locus was only observed in tumors from smokers. Considering the prevalence of nonsmokers in the younger cohort in this oral cancer study, the absence of deletions of $p 16$ in this group is not that surprising.

In light of the absence of $p 16$ deletions in younger patients in this study, it is possible that $p 16$ deletions do not play a comparable role in oral SCC occurring in younger adults as in classic oral SCC seen in older adults. Of course, $p 16$ may be inactivated by other methods not explored in this article such as methylation or mutation.

Human papillomaviruses (HPV) have been implicated in oral and HNSCC. ${ }^{34,35}$ This study does not aim to address the role of $p 16$ expression and HPV infection in young adults, but clearly the role of HPV infection in SCC in young adults needs to be further explored.

In this study, far fewer alterations were found on chromosome 3 in the young nonsmokers compared with the other cohorts. The diminished role for chromosome 3 aberrations found in this group of oral cancers contradicts Partridge et al, ${ }^{36}$ who found that loss of heterozygosity on chromosome $3 p$ was not confined to patients exposed to heavy 
smoking or alcohol consumption and was present at an early stage in the disease, suggesting that this genetic alteration may be a fundamental event for all oral cancer.

The data generated in this study indicate that the aberration profile in the younger non-smokers is remarkably different from the profile classically found in oral cancer. One limitation of this study is the small sample size. This is to be expected, because no one center has experience with a large cohort of young patients with SCC. However, the findings are too clearly defined to be dismissed.

The younger nonsmokers seem to have very few gains and losses at the sites established in the literature as commonly altered in oral cancer. This suggests that deletions of tumor suppressor genes such as $p 16$ and deletions of the short arm of chromosome 3 , which are alterations commonly found in oral cancer, may have a diminished role to play in oral cancer developing in young people.

With a notable absence of traditional risk factors in a significant portion of young people who had oral cancer develop, ${ }^{9,17}$ other possible risk factors have been explored, for example occupation, ${ }^{37}$ $\operatorname{diet}^{38}$ genetic and familial factors, ${ }^{39}$ and viruses. ${ }^{34}$ These risk factors need to be further explored to establish the causative factors underlying oral cancer in the young.

\section{CONCLUSION}

This work represents the first study applying age-discriminated oral cancers to a CGH array. A marked difference in the number of aberrations is evident, with the younger nonsmokers showing considerably lower numbers of aberrations than the other groups. The aberration profiles of the younger group, in particular the younger non-smokers, differs distinctly from the older group.

Such significant difference in genomic profiles, with absence of deletions of tumor suppressor gene CDKN2A ( $p 16$ ), suggests that a different molecular mechanism for oral carcinogenesis in these young nonsmoking patients may be in place; however, this alternative mechanism responsible for the development of oral cancer in young people remains to be explained. The pattern of oral cancer is changing, and it can no longer be assumed that only older male smokers are likely to have this disease develop. Further work on oral cancer with special attention paid to young nonsmokers will provide insight into the complex molecular mechanisms responsible for the development of this disease in an increasing number of young people.

\section{REFERENCES}

1. Nagpal JK, Das BR. Oral cancer: reviewing the present understanding of its molecular mechanism and exploring the future directions for its effective management. Oral Oncol 2003;39:213-221.

2. Jemal A, Murray T, Samuels A, Ghafoor A, Ward E, Thun MJ. Cancer statistics 2003. CA Cancer J Clin 2003;53:526.

3. Sarkaria JN, Harari PM. Oral tongue cancer in young adults less than 40 years of age. Rationale for aggressive therapy. Head Neck 1994;16:107-111.

4. Schantz SP, Yu GP. Head and neck cancer incidence trends in young Americans, 1973-1997, with a special analysis for tongue cancer. Arch Otolaryngol Head Neck Surg 2002;128:268-274.

5. Macfarlane GJ, Boyle P, Scully C, Oral cancer in Scotland: changing incidence and mortality. BMJ 1992;305: 1121-1123.

6. Cowan CG, Gregg TA, Kee F. Trends in the incidence of histologically diagnosed intra-oral squamous cell carcino ma in Northern Ireland, 1975-89. Br Dent J 1992;173: 231-233.

7. Kuriakose M, Sankaranarayanan M, Nair MK, et al. Comparison of oral squamous cell carcinoma in younger and older patients in India. Oral Oncol 1992;28B:113120.

8. Tsukuda M, Ooishi K, Mochimatsu I, Sato H. Head and neck carcinomas in patients under forty years of age. Jpn J Cancer Res 1993;84:748-752.

9. Mackenzie J, Ah-see K, Thakker N, et al. Increasing incidence of oral cancer amongst young persons what is the aetiology? Oral Oncol 2000;36:387-389.

10. Hermsen M, Guervos MA, Meijer G, et al. New chromosomal regions with high-level amplifications in SCCs of the larynx and pharynx, identified by CGH. J Pathol 2001; 194:177-182.

11. Brzoska PM, Levin NA, Fu KK, et al. Frequent novel DNA copy number increase in squamous cell head and neck tumors. Cancer Res 1995;55:3055-3059.

12. Struski S, Doco-Fenzy M, Cornillet-Lefebvre P. Compilation of published comparative genomic hybridisation studies. Cancer Genet Cytogenet 2002;135:63-90.

13. Mantripragada KK, Buckley MG, Benetkiewicz M, et al. High resolution profiling of a $11 \mathrm{Mb}$ segment of human chromosome 22 in sporadic schwannoma using arrayCGH. Int J Oncol 2003;22:615-622.

14. Bentz M, Plesch A, Stilgenbauer S. Minimal sizes of deletions detected by CGH. Genes Chromosomes Cancer 1998;21:172-175.

15. Stears RL, Martinsky T, Schena M. Trends in microarray analysis. Nat Med 2003;9:140-145.

16. Sunny L, Yeole BB, Hakama M, et al. Oral cancers in Mumbai, India: a fifteen years perspective with respect to incidence trend and cumulative risk. Asian Pac J Cancer Prev 2004;5:294-300.

17. Llewellyn CD, Johnson NW, Warnakulasuriya KA. Risk factors for oral cancer in newly diagnosed patients aged 45 years and younger: a case-control study in Southern England. J Oral Pathol Med 2004;33:525-532.

18. Llewellyn CD, Linklater K, Bell J, Johnson NW, Warnakulasuriya S. An analysis of risk factors for oral cancer in young people: a case-control study. Oral Oncol 2004;40: $304-313$. 
19. Rodriguez T, Altieri A, Chatenoud L, et al. Risk factors for oral and pharyngeal cancer in young adults. Oral Oncol 2004;40:207-213.

20. Hermsen MAJA, Joenje H, Arwert F. Assessment of chromosomal gains and losses in oral squamous cell carcinoma by CGH. Oral Oncol 1997;33:414-418.

21. Wolff E, Girod S, Liehr T, et al. Oral squamous cell carcinomas are characterized by a rather uniform pattern of genomic imbalances detected by comparative genomic hybridisation. Oral Oncol 1998;34:186-190.

22. Squire JA, Bayani J, Luk C, et al. Molecular cytogenetic analysis of head and neck squamous cell carcinoma: by comparative genomic hybridization, spectral karyotyping, and expression array analysis. Head Neck 2002;24: 874-887.

23. Gebhart E, Liehr T, Wolff E, Wiltfang J, Koscielny S, Ries J. Loss of $9 \mathrm{p} 21$ is embedded in a complex but consistent pattern of genomic imbalances in oral squamous cell carcinomas. Cytogenet Genome Res 2003;101:106-112.

24. Okafujy M, Ita M, Hayatsu Y, Shinizaki F, Oga A, Sasaki K. Identification of genetic aberration in cell lines form oral SCC by CGH. J Oral Pathol Med 1999; 28:241-245.

25. Weber RG, Scheer M, Born IA, et al. Recurrent chromosomal imbalances detected in biopsy material from oral premalignant and malignant lesions by combined tissue microdissection, universal DNA amplification, and comparative genomic hybridization. Am J Pathol 1998;153: 295-303.

26. Garnis C, Baldwin C, Zhang L, Rosin MP, Lam WL. Use of complete coverage array comparative genomic hybridization to define copy number alterations on chromosome $3 p$ in oral squamous cell carcinomas. Cancer Res 2003;63:8582-8585.

27. Garnis C, Campbell J, Zhang L, Rosin MP, Lam WL. OCGR array: an oral cancer genomic regional array for comparative genomic hybridization analysis. Oral Oncol 2004;40:511-519.
28. Garnis C, Coe BP, Zhang L, Rosin MP, Lam WL. Overexpression of LRP12, a gene contained within an 8q22 amplicon identified by high-resolution array CGH analysis of oral squamous cell carcinomas. Oncogene 2004;23: $2582-2586$.

29. Kallioniemi A, Kallioniemi OP, Sudar D, et al. Comparative genomic hybridization for molecular cytogenetic analysis of solid tumors. Science 1992;258:818-821.

30. Hermsen MA, Meijer GA, Baak JP, Joenje H, Walboomers JJ. CGH-a new tool in cancer pathology. Hum Pathol 1996; 27:342-922.

31. Kinzler KW, Vogelstein B. Cancer susceptibility genes. Gatekeepers and caretakers. Nature 1997;24:761-763.

32. Gollin SM. Chromosomal alterations in squamous cell carcinomas of the head and neck: window to the biology of disease. Head Neck 2001;23:238-253.

33. Sanchez-Cespedes M, Decker PA, Doffek KM, et al. Increased loss of chromosome 9p21 but not p16 inactivation in primary non-small cell lung cancer from smokers. Cancer Res 2001;61:2092-2096.

34. Gillison ML, Koch WM, Capone RB, et al. Evidence for a causal association between human papillomavirus and a subset of head and neck cancers. J Natl Cancer Inst 2000;92:709-720.

35. Mork J, Lie AK, Glattre E, et al. Human papillomavirus infection as a risk factor for squamous-cell carcinoma of the head and neck. N Engl J Med 2001;344:1125-1131.

36. Partridge M, Kiguwa S, Langdon JD. Frequent deletion of chromosome $3 p$ in oral squamous cell carcinoma. Eur J Cancer B Oral Oncol 1994;30B:248-251.

37. Moulin JJ, Mur JM, Wild P, Perreaux JP, Pham QT. Oral cavity and laryngeal cancers among man-made mineral fiber production workers. Scand J Work Environ Health 1986;12:27-31.

38. Franceschi S, Favero A, Conti E, et al. Food groups, oils and butter, and cancer of the oral cavity and pharynx. BJC 1999;80:614-620.

39. Friedlander PL. Genomic instability in head and neck cancer patients. Head Neck 2001;23:683-691. 